\title{
LA IGLESIA GADITANA ANTE LA CRISIS DEL ANTIGUO RÉGIMEN (1800-1833)
}

\author{
POR \\ Arturo Morgado \\ Universidad de Cádiz
}

\section{Rasumen}

Los primeros años del siglo XIX constituyen una etapa crítica en la historia de la Iglesia española ante el descenso de los efectivos clericales, el deterioro de sus bases económicas y la incidencia de los avatares políticos. Este trabajo pretende analizar este proceso en el marco concreto de la diócesis de Cádiz.

\section{Anstract}

Cádiz Church in ancient regime crisis (I800-1833)

The first years of the XIXth century were a critical period in the Spanish Church's History. They saw the disminution of the clerical effectives, the crisis of its economical power, and the influence of the political changes. This work to pretend to analyze these transformations in the diocese of Cadix.

\footnotetext{
ABREVIATURAS:

ACC Archivo Catedralicio de Cádiz

ADC Archivo Diocesano de Cúdjz

AHN Archivo Histórico Nacional

AHPC Archivo Histórico Provincial de Cádiz

AMC Archivo Municipal de Cádiz

ASV Archivo Secreto Vaticano
} 
Los primeros años del siglo XIX fueron bastante críticos para la Iglesia española ${ }^{1}$. Sus crecientes dificultades económicas, como consecuencia del proceso desamortizador iniciado con Godoy, y la cada vez más difícil percepción del producto decimal; las apuestas políticas realizadas durante este período, y su incidencia, parece ser cada vez más reducida, sobre la vida cotidiana de la feligresía; conformarán un panorama que poco tiene que ver con la halaguieña situación vivida aún en tiempos de Carlos III, cuando sus bases económicas eran sólidas, su alianza con el Trono, indiscutida, y su influencia ideológica, considerable. No obstante, a pesar de contar con una visión de conjunto bastante válida sobre la Iglesia española de este período (centrada en exceso, bien es cierto, en los aspectos políticos, y dejando de lado otras cuestiones como reclutamiento del clero, situación económica, o formación cultural), aún queda bastante por matizar los posibles comportamientos regionales. Este trabajo pretende ser una modesta aportación en este sentido, analizando la situación de la Iglesia gaditana durante el primer tercio del siglo XIX.

\section{UN RECLUTAMIENTO EN CRISIS.}

El clero gaditano del primer tercio del siglo XIX tenía buenos motivos para añorar la época inmediatamente anterior, puesto que ya nunca volverá a encontrar la plenitud numérica del pasado. Los datos son bastante ilustrativos en este sentido: en la urbe gaditana, que contaba en 1786 con 1142 clérigos, solamente habrá 838 en 1801 y 375 en 1830 , aunque los datos de este último padrón estén incompletos por cuanto omite alguna de las comunidades religiosas existentes en este período ${ }^{2}$. El resto de la diócesis atraviesa una situación similar: en Alcalá de los Gazules había en 178757 eclesiásticos seculares, frente a 27 en 1801 , en Chiclana 45 y 35 (y 38 en 1805), en Jimena 35 y 20 , en San Fernando 54 y 36 (y 35 en 1804), en Tarifa 60 y 44 respectivamente 3

\footnotetext{
1 Un panorama de la situación de la Iglesia española durante este período, en CALLAHAM, W.J., Iglesia, poder y sociedad en España /750-1874, Madrid, 1989; CASTELES, J.M., Las asociaciones religiosas en la España contenporánea (1767-1965), Madrid, 1973; CUENCA TORIBlo, J.M., Aproximación a la historia de la Iglesia contemporánea en España, Madrid, 1982; VVAA, Historia de la Iglesia en Espaiia, vol. V, Madrid, BAC, 1979; LA PARRA LOPEZ, E, El primer liberalismo español y la Iglesia. Las Cortes de Cádiz, Alicante, 1985. Monografíns regionales en Hugueruela, L., El clero de Toledo desde 1800 a 1823, Madrid, 1979; y BADA, J., L' Esglesia de Barcelona en La crisi de l'Antic Régìn I808-1833, Barcelona, 1986.

2 Morgado Garcia, A., Iglesia y sociedad en el Cádiz del siglo XVII, Cádiz, 1989, p. 19; PEREZ SERRANo, J., Cádiz la ciudad desnuda. Cambio económico y modelo demográfico en la formación de la Andalucía contemporánea, Cádiz, 1992, p. 178.

3 MORGaDo GARClA, A., "La crisis de la Igleșia gaditana darante el reinado de Carlos IV", La España de Carlos IV, Madrid, [992, p. 116.
} 
Similar crisis padecen las órdenes religiosas, muy afectadas por el proceso de secularización. En 1823 los franciscanos de Puerto Real contaban con 18 religiosos (frente a 46 en 1787), los agustinos de Medina con 3 (12), los descalzos de Tarifa con 9 (19), los mínimos de Conil con 11 (21 en 1768), los agustinos de Chiclana con 14 (18 en 1787), Ios carmelitas de San Fernando con 19 (28 en 1787), los mercedarios calzados de Algeciras con 15 (14), los agustinos de Cádiz con 34 (58), los mercedarios de Cádiz con 25 (76), los capuchinos de Cádiz con 27 (81), los descalzos de Cádiz con 32 (84), los franciscanos de Cádiz con 44 (110), los dominicos de Cádiz con $30(60)^{4}$.

¿Qué es lo que ha ocurrido? Sin negar la incidencia de factores meramente vegetativos (las sucesivas epidemias de fiebre amarilla, las consecuencias de la Guerra de la Independencia), todo ello se origina por el declive, cada vez más acentuado, de las ordenaciones sacerdotales, ante el fin de las fundaciones de nuevas capellanías (y la desamortización de muchas de ellas a partir de 1799), que hasta el momento habían constituido el soporte de la congrua de todos aquéllos que optaban por ingresar en el clero secular. Tal como reconocía el obispo Fray Domingo de Silos Moreno en 1830, "el ramo de capellanias es casi nulo por no pagarse los réditos de los capitales vendidos y no resta para proveer a la iglesia de los ministros necesarios otro medio que el de la ereccion de patrimonios tan poco conforme al espiritu de aquellas sino en caso de necesidad"5. Y no había otras alternativas, dado el escaso aparato parroquial y beneficial de la diócesis ${ }^{6}$, incapaz por ello de asegurar la subsistencia de un clero numeroso.

El clero regular, por su parte, se verá fuertemente afectado por las secularizaciones: según un informe remitido por el prelado en 1823, desde el 30 de septiembre de 1820 habían pasado al clero secular 37 franciscanos observantes, 27 descalzos, 3 terceros, 2 capuchinos, 8 dominicos, 5 agustinos calzados, 1 agustino descalzo, 20 carmelitas descalzos, 26 mercedarios descalzos, 5 mercedarios calzados, 1 hermano de San Juan de Dios, 13 minimos, 1 escolapio, 1 cartujo, y 1 trinitario calzado, lo que daba un total de 151 monjes $^{7}$, habiendo sido suprimidas por no reunir el número mínimo de religiosos establecido en 1821 las comunidades de franciscanos observantes de San Fernando, mínimos de Puerto Real, hermanos de San Juan de Dios, mínimos y francisca-

4 Morgado Garcia, A., "Las bases humanas y económicas del clero de la diócesis de Cádiz en el siglo XVIIl", Congreso de Historia de Andalucía, Córdoba, 1991; ADC, Manuscritos, lib. 1121 , Estado de la diócesis de Cádiz en 1823.

s ADC, Reales Ordenes, leg. 26.

6 15 parroquias, 41 curas y 43 beneficios en 1784-1785 (ANTON SOLE, P., La Iglesia gadirana en el siglo XVII, Cádiz, 1994, p. 87).

7 ADC, Manuscritos, lib. 1121, Estado de la diócesis de Cádiz 1823. 
nos descalzos de Medina, mínimos de Alcalá, franciscanos observantes de Jimena, mercedarios y franciscanos observantes de Vejer, y los franciscanos observantes y mercedarios descalzos de San Roque ${ }^{8}$, si bien muchas de ellas serían restablecidas tras el Trienio. La situación empeoraría en muchos casos con el tiempo, a juzgar por los conventos con menos de doce religiosos existentes en la diócesis en 1835: los dominicos de Alcalá (5 frailes), los franciscanos de Jimena (3), Tarifa (9), Medina (8), y Puerto Real (8), los agustinos de Chiclana (7) y Medina (7), los carmelitas de San José del Valle (5) y del Cuervo en el término de Medina Sidonia (6), los mercedarios de Vejer (2), y la Almoraima (7), los hermanos de San Juan de Dios de Medina (5), y los mínimos de Puerto Real (7), Conil (6), Medina (7), Alcalá (6) y Jimena (4)9.

El declive de las ordenaciones sacerdotales tampoco facilitaba una recuperación. Si en los años noventa del siglo XVIII un total de 279 individuos recibieron el presbiteriado en la diócesis gaditana, este número ascenderá a tan sólo 111 en la década de 1800, 250 en la de 1810 (incremento artificial que ha de explicarse por la afluencia de numerosos clérigos foráneos durante el asedio francés de la ciudad), 162 en la de 1820 , y tan sólo 71 entre 1830 y $1834^{10}$. La Iglesia gaditana de este período contará con unos cuadros numéricos cada vez más reducidos.

\section{UN PODER ECONOMICO EN DECLIVE.}

Si precaria era la situación humana de la Iglesia gaditana, no lo será menos la económica. Los 8.697 .000 reales a los que ascendieron las rentas beneficiales de los eclesiásticos gadicenses en 1799 constituirán, sin duda alguna, un máximum que ya nunca volvería a ser alcanzado: en 1800-1808 la media anual es tan sólo de 8.374 .000 reales, y aún no se habían iniciado las grandes dificultades ${ }^{11}$.

La primera de ellas: la crisis del diezmo, que afectará, obviamente, a los perceptores del mismo, fundamentalmente el obispo, el capítulo catedralicio y los beneficios simples y las fábricas parroquiales de la diócesis, para todos los cuales el producto decimal era, sencillamente, básico para su economía. Los prelados, por ejemplo, contaban con un patrimonio mueble muy reducido, que en 1823 solamente comprendía una casa en Puerto Real y algunas hazas de

\footnotetext{
ADC, Reales Ordenes, leg. 25.

9 ADC, Reales Ordenes, leg. 27.

10 Morgado Garcia, A., El clero gaditano a fines del Antiguo Régimen. Estudio de las órdenes sacerdotales (/700-/834), Cádiz, 1989.

" ACC, Sección 10, Libros de subsidios de 1777-1802 y 1807-1809. 
tierra en Jerez y Vejer, con unas rentas anuales de 15.772 reales $^{12}$. No mucho mejor era la situación de las fábricas parroquiales: es cierto que el producto de los bienes inmuebles de la catedral gaditana ascendía ese mismo año a 212.152 reales, pero ello contrasta sobremanera con la situación de las parroquias de Puerto Real (1940), San Juan Bautista de Chiclana (1900), Medina Sidonia (7812), Conil (8387), Alcalá de los Gazules (7326), Castellar (200), Jimena (254), San Mateo de Tarifa (960), Vejer (5414), Paterna (220), y las parroquias gaditanas del Rosario (1575) y San Antonio (2040), careciendo incluso de bienes propios las parroquias de Santa Cruz y San Lorenzo en Cádiz, y las de Algeciras, San Roque, Los Barrios y San Sebastián de Chiclana ${ }^{13}$. Y la crisis del diezmo era una realidad, tal como reflejan estos balances de las rentas anuales de los prelados gaditanos (las del cabildo siguen una coyuntura idéntica), que nos revelan un mantenimiento en los primeros años del siglo XIX, un hundimiento durante la Guerra de la Independencia, una marcada recuperación durante el Sexenio absolutista, y una crisis irreversible tras el Trienio:

\section{RENTAS DECIMALES DE LOS OBISPOS.}

\begin{tabular}{ccccc} 
& 1. & 2. & 3. & 4. \\
\hline 1800 & 2769 & 333 & 217.098 & 483.090 \\
1801 & & & 151.932 & 347.697 \\
1802 & & & 166.304 & 363.146 \\
1803 & & & 227.012 & 442.280 \\
1804 & & & 185.029 & 387.534 \\
1805 & & & 235.001 & 240.297 \\
1806 & 4915 & 750 & 228.143 & 358.429 \\
1807 & 4208 & 546 & 206.926 & 411.757 \\
1808 & 6790 & 786 & 151.847 & 363.072 \\
1809 & 5323 & 431 & 399.112 & \\
1810 & & & 166.380 & \\
1811 & & & 43.101 & \\
1812 & & & 92.545 & \\
1813 & & & 156.375 & \\
1814 & & & 243.377 & \\
1815 & & & 231.366 & \\
1816 & & & 219.609 &
\end{tabular}

12 ADC, Manascritos, lib. 1121, Estado de la diócesis de Cádiz 1823.

13 ADC, Manuscritos, lib. 1121, Estado de la diocesis de Cadiz 1823. 
RENTAS DECIMALES DE LOS OBISPOS. (Continuación)

1.

\begin{tabular}{lccc} 
& 1. & 2. & 3. \\
\hline 1817 & & & 165.511 \\
1818 & & 174.222 \\
1819 & & 256.375 \\
1820 & & 96.522 \\
1823 & 3025 & 439 & 43.524 \\
1824 & 2469 & 224 & 58.066 \\
1825 & 2986 & 363 & 52.902 \\
1826 & 4496 & 609 & 60.164 \\
1827 & 6687 & 750 & $72.96]^{14}$ \\
$1 .=$ & \\
2.= Trigo en fanegas. & & \\
3.= Rentas de maravedises en reales. \\
4.= Rentas totales en reales.
\end{tabular}

Las lamentaciones, por supuesto, no se hicieron esperar. En 1819 se exponía en el cabildo catedralicio cómo "obligados los pueblos por las tropas francesas a pagar los diezmos adoptaron los labradores varios efugios para eximirse de pagar...mas libres ya no saben los labradores distinguir lo que dicta un gobiemo de otro, si en aquel estaban excusados porque no se daban a los legitimos participes de diezmos, en el dia urge al derecho divino y eclesiastico para los que sirven al altar del altar vivan"15. Al año siguiente se recibía una queja de los beneficiados de Alcalá, que mostraban cómo "en los labradores de aquel termino entusiasmados con la idea de una mal entendida libertad se observaba harta aversion a pagar los diezmos de sus cosechas que con razon podia temerse no ser suficiente toda la vigilancia para lograr una completa y justa recoleccion de los granos"16. La situación llegaría a ser tan grave que en 1827 el obispo Fray Domingo de Silos Moreno se vería obligado a publicar una pastoral en la que afirmaba la ilicitud de no pagar el diezmo, aunque reconociendo que si "bien es cierto que las rentas de los obispos y demas eclesiasticos no se han empleado comúnmente sino en el alivio de la humanidad doliente afligida o menesterosa...en el día no podemos hacer lo que se hizo en otros tiempos porque no hay la religión la piedad el arreglo de costumbres la obediencia y respeto a los mandamientos de la iglesia y del soberano que ha-

14 ACC, Libros decimales y de stbsidio y excusado.

15 ACC, Sección 1, serie I, lib. 5I, fol. 90.

is ACC, Sección 1, serie 1, lib. 51, fol 75.

De la Iglesia Andaluza

Hispania Sacra 48 (1996) 
bia en aquellos, es porque bien al contrario cunden y se propagan hoy la irreligión, la impiedad, el desarreglo en la conducta y un desprecio altanero de lo más santo y de lo más sagrado"17.

Un segundo elemento de crisis vendrá dado por la pérdida del patrimonio eclesiástico como consecuencia de las desamortizaciones iniciadas en 1799. Entre 1801-1808 fueron vendidas en la urbe gaditana 204 fincas y 42 censos, por un monto económico de 46,2 y 1,3 millones de reales respectivamente, pertenecientes en su inmensa mayoría a obras pías. Durante el Trienio Liberal la Desamortización afectó en toda la provincia a 365 fincas, en sus dos terceras partes urbanas, que fueron tasadas en 19 millones de reales y vendidas en $52,4^{18}$. Ello empero, no acabaría con el patrimonio de la Iglesia gaditana, que todavía seguirá siendo considerable, a juzgar por la información aportada por el Catastro de Martín de Garay y las averiguaciones realizadas entre 1834 y 1836 previas a la Desamortización de Mendizábal.

RENTAS DE LA IGLESIA GADITANA EN 1818.

\begin{tabular}{lrrrc} 
& P. Real & Alcalá G. & Algeciras & Los Barrios \\
\hline Tierras secano & 9.410 & $(1)$ & 3.060 & 18.089 \\
Huertas & & 2.370 & & \\
Olivares & & $(1)$ & & 2.048 \\
Viñas & & 900 & & 4.834 \\
Molinos & & 8.000 & 37.572 & 26.971 reales \\
Edificios & 36.616 & 64.327 & 40.632 & 317.542 (con San Roque) \\
Total & 46.026 & 75.597 &
\end{tabular}

(1) Muchas explotadas directamente o artendadas en especie.

Fuente: AHPC, Gobiemo civil, cajas 247 y 249, y MORGADO GarCla, A., "Las bases".

Sin entrar en la veracidad o no del Catastro de Martín de Garay ${ }^{19}$ (muchas cifras nos parecen demasiado bajas), lo cierto es que la situación económica de la Iglesia gadicense parece haberse deteriorado fuertemente desde media-

17 SILOS MORENo, Fray Domingo de, Exhortación del Obispo de Cádiz a sus anados diocesanos, Cádiz, 1827, p. 28.

18 GONZAlez MOLjNA, M., y GOMez OLIVer, M., "Beneficios del comercio colonial, vales reales e inversiones inmobiliarias en Cúdiz (1798-1823)", FONTANA, J., El comercio libre entre España y América Latina 1765-1824, Madrid, 1987.

ig Un buen estudio local en LOZANO SALADO, M.D., Jerez a principior del siglo XIX: urbanismo y propiedad, Jerez de la Frontera, 1993. 
dos del siglo XVIII. Tomemos, por ejemplo, el caso de los edificios urbanos: en 1755 sus rentas sumaban un total de 36.364 reales en Alcalá de los Gazules, 52.256 en Puerto Real, y 58.554 en San Roque (que englobaba además a Algeciras y Los Barios), siendo las cifras de 1818 bastante inferiores. En las tierras nos encontraremos con una situación similar: su producto anual en la época del Catastro garantizaba 197.107 reales en Alcalá de los Gazules, 153.569 en Puerto Real, y 118.754 en San Roque. El patrimonio urbano parece haber resistido mejor, pero el rústico se encuentra en una situación sumamente deteriorada.

De todas formas, y como es evidente, el proceso desamortizador no concluiría hasta una vez finalizado el período que nos ocupa. Todavía en 1835 1836 los conventos gaditanos contaban con unas propiedades de relativa entidad: los mínimos de Alcalá poseían varias huertas, 26 casas y 60 censos ${ }^{20}$, los mercedarios de la Almoraima (en 1822) 16 casas y algunas fincas de tierra ${ }^{21}$, las agustinas de Chiclana 15 casas, 30 predios rústicos y 136 censos $^{22}$, los mínimos de Jimena algunas huertas, 34 casas y 175 censos $^{23}$, sus compañeros de religión de Puerto Real 5 casas y algunos pedazos de tierra ${ }^{24}$, los mercedarios de Vejer (en 1821) más de 400 aranzadas de tierra y un centenar de oli$\operatorname{vos}^{25}$, los mínimos de Conil fincas, 4 casas y 60 censos $^{26}$...sin contar con el patrimonio, de mayor entidad, de los conventos gaditanos ${ }^{27}$.

Un tercer elemento, finalmente, radicará en la crisis de la piedad barroca, con el subsiguiente descenso de encargos de misas, sufragios y funerales ${ }^{28}$, lo que afectará de modo importante a los párrocos, para las cuales estas obvenciones eran básicas para su subsistencia. Ya en 1803 los curas dirigían un memorial al cabildo municipal gaditano en el que exponían cómo

"En una ciudad tan opulenta donde sus ultimos servidores gozan de un sueldo porque para ocurrir a su subsistencia solo los pastores carecen del preciso para vivir y sin esperanza de remedio. Casi todos los que la socorrieron en su grave calamidad del año de $97 \mathrm{y}$ en la gravisima del de 800 permanecieron y han logrado una decorosa recompensa que los alienta a mayores servicios por la patria al paso que recogen los hermosos frutos de la gratitud de esta solamente los parrocos que en ambas fuimos victimas por su socorro tenemos una triste experiencia de que el abatimiento ha sido nuestro premio sin

\footnotetext{
20 AHPC, Hacienda, caja 1235.

21 AHPC, Hacienda, caja 1236.

22 AHPC, Hacienda, caja 1236.

23 AHPC, Hacienda, caja 1238.

24 AHPC, Hacienda, caja 1239.

25 AHPC, Hacienda, caja 1239.

26 AHPC, Hacienda, caja 1257.

27 Morgado GarCia, A., Iglesia y sociedad en el Cádiz del siglo XVIII, Cádiz, 1989.

${ }^{28}$ Pascua SANChez, M.J., Vivir la muerie en el Cádiz del Setecientos (I675-180I), Cádiz, 1990.

De la Iglesia Andialuza

Hispania Sacra 48 (1996)
} 
que haya no ya quien nos lo otorgue sino que no contribuya a acabarnos de abatir entre el oscuro polvo de la miseria.

Ningun ciudadano de Cadiz nos paga el diezmo ni la primicia de sus frutos ninguno se acuerda de nosotros para sus oblaciones voluntarias ni aun los ricos acuden con las que espontaneamente deben ofrecernos los domingos y otras fiestas...la cuarta funeral no es en Cadiz nutestra ni tampoco to son ya los funerales porque una preocupacion general del feligres contra la que nada prevalece porque le es util casi los ha hecho desaparecer de nuestras iglesias. Los eventuales derechos de estola...son una contribucion ilegal por falta de autoridad legitima en su imposicion...los moradores de Cadiz no estan obligados a contribuir por la administracion del bautismo ni se les exige algo sino cuando solicitas la pompa por el matrimonio ordinariamente dan un peso nadie los obliga ni les pide el pago de las velaciones y lo que es mas raro ni al del funeral...se numeran escritas las partidas de 3976 difuntos sin que se haya celebrado mas funerales que $938 . .$. los bautismos deben distinguirse en dos clases a saber unos tienen pompa y los otros no. Estos que son incomparablemente mas que aquelfos...producen a los curas lo que el padre o padrino voluntariamente les ofrecen. Esta ofrenda (de que dan la quinta parte al sacristan) jamas excede y no llega de ordinario a 20 reales de vellon...,mas aquellos que tienen pompa y se conocen por los nombres de capa organo aparador media capilla y capilla entera aunque valen algo ni estan en uso los de mas precio que son los ultimos...por lo respectivo a matrimonios conocen los curas cinco diferencias de precio el cual siempre se parte cuando alguno de los contrayentes es castrense y sucede con frecuencia. Los pobres nada pagan los que no lo son tanto contribuyen 7 y medio reales para los siete curas los que casan en el templo 15 los que en su casa 30 y los que en secreto 60 . Estas dos ultimas clases que valen mas son por desgracia las frecuentadas menos ${ }^{\prime \prime 2} y$.

La situación llegó a tal gravedad, que el número de curas existente en la ciudad fue reducido de siete a seis ante la imposibilidad de ser mantenidos dignamente $^{30}$. Pero las dificultades, empero, persistieron. En 1826 el cabildo municipal recibía una carta de los curas en la que éstos demostraban nuevamente la cortedad de sus dotaciones, ya que solamente se sostenían "con el pie de altar o limosna que entregan los fieles a la recepcion de los santos sacramentos del bautismo y matrimonio no siendo de pobres, misas de entrada, conducciones de cadaveres o exequias, todo ello antes de 1780 rentaba 40.000 reales, en 1780-1800 25.000, en 1800-1814 15.000 y desde entonces la disminucion ha sido progresiva y ha guardado proporcion con el de las calamidades que han afligido a este pueblo"31. Una real Orden promulgada en 1828 pre tendería solucionar el problema aplicando a los curas la mitad del arbitrio de 4 maravedis en cuartillo de vino impuesto para las obras de la casa capitular y de la cárcel ${ }^{32}$.

No fueron los curas de la urbe gaditana los únicos en lamentarse durante estos difíciles tiempos, puesto que el malestar ante la crítica situación eco-

2) $\mathrm{AMC}, \mathrm{AC}$, lib. 159 , fols. $530-532$ y y $604-606$.

30 AMC, AC, lib. 165 , fols. $525-528$ y 59 I.

31 AMC, AC, lib. 200 , fols. $1239 \mathrm{v}-1247 \mathrm{v}$.

32 AMC, AC, lib. 203, fol. 413v. 
nómica era bastante generalizado entre los clérigos de la diócesis, siendo el problema de fondo muy justamente captado por los capellanes de Medina Sidonia, que en 1827 exponían al prelado cómo "en el dia estan mucho mas caros los viveres y ropa son mas crecidos los costos en aquella epoca el subsidio tocaba a un medio por ciento y en el dia a un cinco o seis entonces existia un gran numero de instituciones de esta clase mas en el dia a causa de las ventas hechas por orden real ha quedado reducido a la tercera o cuarta parte en aquel tiempo las capellanias y memorias estaban dotadas con multitud de fincas urbanas y tributos y actualmente aquellas estan arruinadas las mas y estos casi incobrables por su antiguedad"33 ... los buenos tiempos (que, en realidad, nunca lo fueron tanto) del Antiguo Régimen ya habían finalizado para siempre.

\section{LA SITUACION ESPIRITUAL DE LA DIOCESIS.}

A pesar de este apocalíptico panorama, la vida espiritual en Ia diócesis pudo mantenerse, aunque también con problemas. La situación de los lugares de culto, por ejemplo, que en los medios rurales nunca había sido muy halague$\tilde{\mathbf{n a}}^{34}$, se vería gravemente perjudicada por los daños provocados por las tropas francesas durante la Guerra de la Independencia. Un informe de 1820-1821 mostraba al respecto cómo en San Roque la ropa blanca y de color de la parroquia estaba en una situación deplorable, y las ermitas de San Felipe, la Caridad, Puente Mayorga, Campamento y Línea de Gibraltar carecían de adorno alguno, en tanto la capilla de San Roque había sido saqueada por las tropas francesas. La parroquia de Paterna vivía en la mayor indigencia de ornamentos y misales. En Los Barrios la fábrica era tan pobre que ni siquiera podía comprar cera. En Algeciras la situación económica de ésta era continuamente deficitaria. En Jimena, por último, faltaban en las parroquias vasos sagrados, ornamentos y alhajas ${ }^{35}$.

Y el raquítico marco parroquial de la diócesis (según la visita ad limina de 1824 había en todo el obispado 20 parroquias, tres iglesias auxiliares y diez parroquias castrenses) ${ }^{36}$ provocaba que, en muchos casos, la infraestructura cultual fuese insuficiente para atender las necesidades espirituales de la feligresía. El vicario de Paterna informaba en 1816 cómo "dos misas no mas se

\footnotetext{
33 ADC, Secretaría, Despacho Silos Moreno, Medina 1824-1829.

34 Cfr. ADC, Secretaría, leg. 5 I1-I, Visitas pastorales 1803-1807.

35 ADC, Varios, leg. 2304, Alhajas y ornamentos pedidos para Ias iglesias del obispado de Cadiz (I820-1821),

36 ASV, Visitas ad limina, Cádiz, copia existente en el Archivo Diocesano de Cádiz. 
dicen los dias festivos en todo este distrito la una en la capilla susodicha (la Ina) y la otra en el valle (San José del Valle) quedando desiertos de este auxilio todos los demas punto en donde ya por la reunion de cortijos y ya por otras circunstancias hay concurrencia de gentes que careciendo de este auxilio las muchas distancias no les proporcionan facilidad de asistir a los puntos sobredichos...los oratorios que estaban en otro tiempo piadosamentre erigidos a expensas de los dueños de los cortijos quienes se encargaban de llevar sacerdotes que en los dias festivos facilitasen a los trabajadores el cumplimiento de este precepto tambien han cesado"37. Hubo, empero, algunos conatos de solucionar esta situación. El obispo Francisco Javier Cienfuegos tras la Real Orden del 22 de octubre de 1821 que disponía la conversión en parroquias de los conventos suprimidos exponía cómo "tres iglesias hay de regulares que son a mi entender de primera necesidad su habilitacion de ayudas de parroquias. Primera la de San José del Valle en aquella parte del termino de Jerez de la Frontera que pertenece a esta diocesis la cual era del suprimido convento de carmelitas descalzos. Esta dista tres leguas de mal camino del pueblo inmediato que es Paterna de Ribera y en sus inmediaciones hay varios caserios y chozas de labradores pobres en que se reunen como hasta quinientas pesonas. La segunda es la iglesia del Cuervo convento suprimido de la misma religion en el termino de Medina Sidonia cuyas circunstancias son iguales a la anterior. Ultimamente la iglesia de mercedarios descalzos de la Almoraima dista una legua de Castellar y esta situada a la falda de un cerro elevado donde esta aquella poblacion de donde resulta que los labradores de aquellos campos mas acuden por el pasto espiritual de esta iglesia que a la de la villa"38. Varios años después, Fray Domingo de Silos Moreno reflejaba la situación de la capilla de la Divina Pastora de Facinas, a tres leguas de distancia de Tarifa "y en medio de su vasta y dilatada campiña donde concurren a oir misa y cumplir con los preceptos de confesion y comunion infinitos fieles tanto de los caserios inmediatos como de los demas cortijos y ranchos. El estado material del edificio es deplorable, la capilla se halla en alberca sus techos arruinados y las paredes maltratadas de resulta de la invasion...el santo sacrificio de la misa se celebra actualmente en la sacristia del santuario la que es tan estrecha y reducida que apenas puede contener el altar y una docena de personas viendose los demas fieles a entrar a campo raso durante el sacrificio"39 , destinando a dicha iglesia la renta de uno de los beneficios simples existentes en Tarifa para paliar la situación.

${ }^{37}$ ADC, Secretaría, leg. 82.

38 ADC, Reales Ordenes, leg. 25.

39 ADC, Despacho Silos Moreno, Tarifa 1824-1833. 
Las cofradías, más de 170 en $1824^{40}$ siguieron gozando de buena salud durante esta época, conservando muchas de ellas su patrimonio económico ${ }^{41}$ y renovando otras sus constituciones y estatutos ${ }^{42}$. Algunas siguieron desarollando sus actividades asistenciales, como la hermandad de la Santa Caridad de Alcalá de los Gazules, que en la década de 1800 tuvo a su cargo el sepelio de 205 personas, en la de 1810 de 127 , en la de 1820 de 184 , y en la de 1830 de $346^{43}$. Continuaron las procesiones de Semana Santa, aunque a veces comience a vislumbrarse la política anticlerical de los liberales, como el 23 de marzo de 1814, cuando el ayuntamiento gaditano las prohibía "por regla de buen gobierno"44. Pero lo más corriente, empero, era que el cabildo municipal siguiera manifestando su apoyo oficial a muchas de estas congregaciones, concediendo en $1815^{45}$ y $1816^{46}$ autorización a la hermandad del Santo Entierro para que procesionara el viernes santo por la noche, o se acordándose en 1830 remitir a la diputación de Patronatos la súplica formulada por las hermandades del Santísimo y Animas de la suma de 4000 reales del patronato de Melchor de Cuéllar para la organización de las procesiones pascuales ${ }^{47}$. Dentro de esta línea de apoyo oficial destaca la aceptación que encontró entre los capitulares la propuesta formulada el 30 de septiembre de 1815 por el diputado del común Manuel Derqui y Tasara de "que todos los capitulares presentes y futuros se incorporen a la hermandad del Nazareno por el hecho de ser capitulares bajo el supuesto de que no tienen otra contribucion ni pension que las limosnas voluntarias"48.

Las fiestas religiosas, a pesar de su permanencia (alusiones, por ejemplo, a la procesión de San Sebastián en $1815^{49}, 1820^{50}, 1822^{51}$, y 1825 , aunque no se celebrara en $1824^{52}$ ), se vieron afectadas en más de una ocasión por las penurias económicas de la época (en 1821 el cabildo municipal suprimía el gasto de las fiestas de San Antonio, María Magdalena, San Roque, la Virgen

\footnotetext{
40 ASV, Visitas ad limina, Cádiz, copia existente en el Archivo Diocesano de Cádiz.

41 AHPC, Hacienda, cajas 1257 y 1262, Cofradías que presentaron relación de sus bienes en $1821-1822$.

42 Vid. al respecto ADC, Secretaría, leg. 511-I, Visitas pastorales 1803-1823; y AHPC, Gobierno civil, cajas 272 y 2725 , relaciones de cofiadías de 1835 .

4 ADC, Manuscritos, lib. 436.

44 AMC, AC, lib. 173, fol. 100.

4.5 AMC, AC, lib. 176, fol. $818 \mathrm{v}$.

46 AMC, AC, lib. 178, fol. 784 .

47 AMC, AC, lib. 208 , fol. 226.

$48 \mathrm{AMC}, \mathrm{AC}, 1 \mathrm{ib} .176$, fol. 924

49 AMC, AC, lib. 175, fol. 85.

so AMC, AC, lib. 186, fol. 108v.

st AMC, AC, lib. 189, fol. 346v.

52 AMC, AC, lib. 195, fol. 110 . 
del Rosario, Todos los Santos, San Carlos Borromeo y San Sebastián $)^{53}$. La principal siguió siendo el Corpus, que en 1814 ocasionara al cabildo municipal unos gastos totales de $27.796,17$ reales $^{54}$, y que en 1819 los regidores diputados de fiestas definieran como "la principal y mas solemne que debe llamar su atencion por lo augusto de su objeto y por los preparativos que exige"55.

La siempre precaria situación de la beneficencia se vio agravada por las desamortizaciones de este período y por los intentos por parte de los liberales de adscribir al Estado o al Municipio lo que hasta el momento había sido prácticamente un monopolio de la Iglesia. Un claro ejemplo al respecto viene dado por el Hospital de san Juan de Dios, del que en 1822 se hiciera cargo la Junta local de Beneficencia ${ }^{56}$, aunque al año siguiente pasara de nuevo al control de los hermanos. Una noticia de los establecimientos benéficos existentes en la ciudad en 1834 nos ilustra acerca de la situación económica, no siempre halagueña, de muchos de ellos. La casa de expósitos ${ }^{57}$, por ejemplo, cuyas fincas de patronatos fueran desamortizadas en 1806 y 1807 , contaba en 1828 con una renta anual de 40.000 reales más una asignación de 130.000 pagados por los gaditanos por impuestos sobre el trigo y semillas. El Hospital de Mujeres, que acogía de 540 a 580 enfermas al año, contaba con unos ingresos anuales de 211.679 reales, procedentes fundamentalmente de fincas urbanas, censos, el arbitrio de un peso por bota de vino que entrara en la ciudad, y el producto de algunos patronatos administrados por el cabildo catedralicio, aunque los gastos superaban los $274.000^{58}$. San Juan de Dios, por su parte, contará en 1806-1810 con unos ingresos de 2,61 millones de reales, y unos gastos de 2,74, atendiendo a 6286 enfermos, de los que murieron 1379, durante dicho período ${ }^{59}$. Persistirá la hospitalidad doméstica, creada a fines del siglo XVIII por el prelado Antonio Martínez de la Plaza, y que todavía en 1815-1816 era capaz de atender a 1572 enfermos y recaudar 109.462 reales de limosnas ${ }^{60}$, aunque en 1818 las cifras hubieran bajado a 780 enfermos y 29273 reales respectivamente ${ }^{61}$.

5.3 AMC, AC, lib. 189, fol. 459v.

54 AMC, AC, lib. 173 , fol. 184v.

ss AMC, AC, lib. 183, fol. 468 .

56 AMC, lib. 189, fol. 316.

\$7 Mayor información en Perez Serrano, J., "La Casa de Expósitos de Cádiz en la primera mitad det siglo XIX: avances y retrocesos de la reforma liberal en el sistema benéfico", Trocadero, 3 . 1991.

58 AMC, AC, lib. 219, fols. 808v-813.

5) AMC, AC, lib. 168 , fols. $65 \mathrm{ss}$.

6il AMC, AC, lib. 179, fol, 287v.

1 AMC, AC, lib. 183 , fol. $159 \mathrm{v}$. 
En los núcleos rurales del obispado el centro benéfico más extendido era la casa de expósitos, de cuya situación nos ilustra un informe de 1827. La de Cádiz contaba por entonces con unos ingresos de 99489 (procedentes sobre todo de arbitrios municipales) reales y unos gastos de 229.752 (destacando 85.000 para las amas de cría, 200 externas y entre 10 y 15 internas, y 80.000 para la manuntención de los niños), dependiendo de ésta la de San Fernando. En Chiclana solamente la caridad de los fieles aseguraba su funcionamiento, aunque el cabildo pagaba el alquiler de la casa y a un ama. La de Medina Sidonia había perdido todas sus propiedades, a excepción de algunos censos, como consecuencia de la Desamortización, debiendo hacer frente a unos gastos anuales de 25.000 reales, contando además con los expósitos que se le remitían desde Alcalá de los Gazules. La de Algeciras estaba bajo tutela del municipio, sin intervención alguna del obispo en su funcionamiento. La de San Roque, afectada también por la Desamortización, contaba con unos gastos anuales de 60 a 70.000 reales, limitándose sus ingresos a los arbitrios impuestos sobre el vino y el vinagre. Los expósitos de Tarifa eran depositados en el Hospital de la Caridad, asegurando su manuntención nuevamente arbitrios municipales, en tanto ni Vejer ni Conil contaban con casa cuna. Y el problema tendía a agravarse, al menos según la opinión del obispo:

\begin{abstract}
"La corrupción de costumbres es tal después de las dos revoluciones que me parece oportuno poner en cada pueblo una casa a propósito para recoger las víctimas de aquella y aun obligar a los ayuntamientos a proporcionar medios para subvenir a su subsistencia...es muy general la corrupción de las costumbres y esto a mi corto entender depende de que no se observan las acertadas providencias con que SM y el Consejo han procurado remediar aquellas. Los amancebamientos tolerados, Ia falta de pudor consentida y no remediada, los divorcios por mero antojo y voluntad, todo esto pide un eficaz remedio para cvitar el aumento de desgraciadas victimas de semejantes excesos"ti2.
\end{abstract}

No obstante, la beneficencia eclesiástica también contaba con otros establecimientos. En 1817 se mantenían en Alcalá de los Gazules el Beaterio fundado a finales del siglo XVIII (que comprendía además un colegio de educandas) y un hospital de hombres; en Conil dos hospicios que alimentaban a un total de 51 viudas; en San Fernando el hospital de San José de ambos sexos, y la Casa de Misericordia para niñas huérfanas; en San Roque el hospital de la Caridad (aunque todas sus posesiones habían sido vendidas) ${ }^{63}$.

De vez en cuando, algunos laicos piadosos acometían la iniciativa de organizar nuevos establecimientos religiosos o benéficos. En 1816 el comerciante gaditano Juan Baptista Ornesagasti exponía sus anhelos de fundar una casa religiosa dedicada a la enseñanza, movido a ello por "lo expuesto que es este

62 ADC, Secretaría, Despacho de Silos Moreno, Patronatos y Casas de expósitos.

63 ADC, Reales Ordenes, Censo de 1817.

De la Iglesia Andaluza

Hispania Sacra 48 (1996) 
pueblo por sus distracciones mercantiles y concurrencias de forasteros y extranjeros de todos los paises a dejar la puerta abierta a unas mujeres que si se aficionan como es temible a el lucro que resulta de sus educandas se veria otra vez la casa convertida en una de distraccion, de ocio y tal vez perjudicial a la policia...y si se reflexiona señor por la necesidad que en este pueblo hay de educacion de niñas no es dudable que antes de emprender esta es necesario afianzar en las maestras la virtud el celo de la religion el amor a sus discipulas y en una palabra la verdadera caridad. $¿$ Que importa que se multipliquen academias y que en ellas se enseñen muchos ramos de lujo y aun de erudicion impertinente si se olvida la santa doctrina y los rudimentos precisos para salvarse y poder gobernar en lo sucesivo las casas y familias con honradez y religion? De aqui es que constituyendo a las maestras en observancia de un instituto religioso y conocido y estando siempre a la inspeccion de sus superiores se lograra mas facilmente la verdadera y solida educacion y se veran cumplidas por entero las beneficas ideas de VM haciendo a este pueblo el bien de que prestase un dechado de educacion sirviendo de modelo a los demas establecimientos que sirva de freno a las demas academias y las contenga caso de excederse". Finalizaba suplicando que el antiguo beaterio fuese destinado a un convento de monjas destinado a la enseñanza, utilizando como libros de texto el Catecismo de Reinoso y de Astete, el Itinerario Historial del P. Andrade, la Infancia Ilustrada, el Año Cristiano y el Catecismo de Pio V.64. Varios años después, en 1830, Doña María Josefa Caule y Cebrián pretendió fundar en San Fernando un convento de carmelitas descalzas en la capilla de Nuestra Señora de la Salud, defendiendo la necesidad de estos establecimientos de clausura "ya para llorar las culpas que se han cometido o para conservar la inocencia...especialisimamente en estos calamitosos tiempos en los que se han resfriado tanto la caridad y multiplicado los delitos de los hombres" ${ }^{165}$.

Pero estas leves pinceladas impresionistas no pueden hacernos olvidar que la piedad tradicional parece estar atravesando una grave crisis durante este período. Señalemos, por ejemplo, la caída espectacular que ofrece el volumen de confirmaciones registradas en la ciudad: 3875 en 1800-1804, 5045 en $1805-1808,4288$ en $1810-1813,3950$ en $1815-1819,6625$ en $1820-1824$, 1818 en $1825-1829,1818$ en $1825-1829,2496$ en 1830-183466, la radicalización experimentada por las declaraciones de todos aquéllos detenidos por la Inquisición por emitir proposiciones ${ }^{67}$...o las continuas lamentaciones de la

${ }^{64}$ AMC, AC, lib. 178, fols. 8[6-829.

65 ADC, Reales Ordenes, leg. 26.

6 ADC, Manuscritos, lib. 42, 49, 339, 340, 342, 445.

${ }^{77}$ MORgado Garcia, A., "Los gaditanos y la Inquisición a fines del Antiguo Régimen", Trivium, 6, 1994. 
jerarquía eclesiástica acerca de las lacras morales de la feligresía, algunas, ciertamente, de añejo contenido, pero otras, por el contrario, reflejando la aparición de nuevos problemas relacionados con la implantación y el desarrollo de las ideas liberales (el prelado Francisco Javier Cienfuegos en la visita ad limina de 1824 se vio obligado a reconocer los "infinita librorum improborum per manus fere omnium circumlata fuerint, quodam in populo christiano disciplina et morum disolutio observatur") $)^{68}$ :

"Lejos de edificarnos la excesiva devocion de la gente vulgar de Tarifa a la sagrada virgen con el titulo de la luz nos ha producido no poco escandato estamos persuadidos que una devocion arreglada a la sagrada virgen nunca puede ser defectuosa pero siempre lo sera una devocion desarregiada...vimos en el dia del señor muchas gentes quedarse sentadas al pasar la majestad sin hacer la mas leve demostracion a todo un dios cuando sabemos que a la presencia de la imagen de la señora hacen todas aquellas demostraciones propias del supremo culto de latria" (Tarifa, visita pastoral de 1801) ${ }^{69}$.

"No olvidando la fraternidad que se eviten cuidadosamentre los escandalos con cspecialidad publicos y los malos ejemplos que ias personas del sexo opuesto se abstengan de desnudeces provocativas, del desmedido lujo y de vanidades desenvueltas, que las gentes de negocios procuren guardar justicia y legalidad en sus tratos huyendo de toda usura, dolo y mala fe, que los magistrados administren puntual y santamente el deposito sagrado de la justicia como al presente mas que nunca se necesita, que todos los vasallos comprendidos en esta diocesis prestandose dociles a las ordenes de las autoridades constituidas aparten sus animos de las sediciones parcialidades tumultos y odios personales y obedezcan con confianza las ordenes y mandatos de sus superiores al mismo tiempo que leales y valerosos concurran con sus personas y bienes a la justa defensa de la causa comun...el patriotismo verdadero no es una virtud gentilicia y vana sino que se halla fundado en las santas leyes de la caridad evangelica y de la justicia, y que la raiz de la corrupcion de costumbres consiste en la falta de educacion de la juventud en la libertad, lujo y relacion que permiten las cabezas de familia a sus propias esposas e hijas que hasta en el santo templos se presentan con trajes indecentes escandalosos y provocativos" (Edicto del obispo Francisco Javier Utrera, 20 de junio de 1808) ${ }^{71 "}$.

"En ningun tiempo ha estado la fe y la religion mas a peligro de perderse entre nosotros. El mayor y mas funesto daño que ha hecho al pueblo español el trato y alianza con los que se han declarado ahora crueles enemigos de nuestra patria ha sido debilitar en muchos borrar en algunos y desfigurar en casi todos la impresion saludable que ha estado grabada en el alma de los españoles sobre la creencia y el respeto de las verdades de nuestra santa fe. Por desgracia hay mas de medio siglo que una tropa de hombres impios disfrazados con nombre de filosofos tomo a su cargo el sacrikegio y desatinado empeño de destruir la religion...cundida esta gente en Francia era fuerza que nos inficionase...vosotros sabeis muy bien los efectos que ha producido esta desventurada mania de libertinaje y de irreligion. Corrupcion de costumbres, discursos licenciosos, olvido de

68 ASV, Visitas ad limina, Cádiz, copia existente en el Archivo Diocesano de Cádiz.

${ }^{69} \mathrm{ADC}$, Secretaría, leg. 510, Visitas pastorales 1800-1803.

70 ADC, Edictos impresos, número 116.

De la Iglesia Andaluza

Hispania Sacra 48 (1996) 
Dios, menosprecio de todo lo sagrado, irreverencia en los templos, odio a sus sacerdotes $y$ total abandono de las practicas de la religion" (Fray Pablo de la Concepcion, 1808) ${ }^{71}$.

"Sera nuestra devocion muy acepta a los ojos del señor si en vez de aquel libertinaje se subroga la compuncion y si en el lugar que ocupo el desorden suceden la devocion y la religiosidad...no se oigan en las casas particulares ni aun ecos de diversiones ni de convites que en otras circunstancias fueron tan frecuentes" (Edicto del Vicario General José Muñoz Raso del 2 de marzo de 1810) ${ }^{72}$.

"No podemos mirar con indiferencia antes bien con imponderablc dolor observamos el practico y escandaloso desprecio que casi generalmente se hace de los dias santos desatendiendo cuanto Dios nuestro señor en su santisima ley nos ordena...las tiendas estan abiertas en estos dias, se verifican compras y ventas como en los de trabajo, se emplean publicamente los menestrales y cortesanos en sus oficios, se continuan las labores de! campo y absolutamente se pretende hacer cesar la observancia de los dias festivos" (Edicto del vicario Mariano Martín Esperanza, 1812)73.

"La descarada animosidad con que se mofa la religion y sus ministros y se ulcera el corazon de los que ya dispuestos a domesticarse con la impiedad y el libertinaje tragan a sorbos continuos el veneno envuelto en la sal del chiste y del sarcasmo...el pueblo se empapa en maximas quue lisonjean la carne y la sangre la religion pierde su fucrza pues roto el freno de las pasiones por el desprecio de las doctrinas y elementos de la moral hecho el babito de canonizar la razon humana en lugar del dogma y de las enseñanzas de la religion se socavan los cimientos del estado y es de toda necesidad su disolucion y el anegarnos en las horrorosas aguas que han sumergido otras naciones" (Carta del Provisor y Vicario Capitular José Muñoz Raso, 15 de abril de $18127^{74}$.

"Procuren santificar estos dias de eterna salud con el grande amor y reverencia a que nos estimula su memoria juntandose para ello cada cual con una compostura modesta y respestuosa en la presencia de Dios eviten por las calles y sitios publico causar el menor escandalo" (Edicto del obispo Juan Acisclo de Vera, 8 de abril de 1816) 15. $^{75}$.

"Santificar los dias consagrados a Dios en lo que se nota el mayor abandono con tanto dolor de las almas religiosas...que celen el honor debido a los templos separando de ellos todos los objetos que puedan distraer la atencion de los fieles especialmente las conversaciones profanas y los trajes y posturas indecentes" (Edicto del obispo Francisco Javier Cienfuegos del 13 de diciembre de 1819$)^{\gamma /}$.

"Son por desgracia bien publicos y notorios los perjuicios y daños que ha cxperimentado nuestra amada patria, la religion santa que profesa, sus dogmas sagrados, su divina moral, y la disciplina de la iglesia por la mal entendida libertad de imprimir, discurrir y hablar a la cual dio motivo la ominosa revolucion empezada el año de 1820...rotos por ésta los diques que oponia a la impiedad la bartera de la Inquisicion se inundaron al momento las ciudades villas y lugares y hasta las mas reliradas aldeas de

$"$ CONCEPCION, Fray Pablo de la, Sermon...para la bendicion de las banderas del regimieno de voluntarios de Cádiz, Cádiz, 1808.

72 ADC, Edictos impresos, número 122.

${ }^{73}$ ADC. Edictos impresos, número 128.

74 ADC, Reales Ordenes, leg. 20, "Carta del provisor y vicario capitular Joseph Muñoz Raso 15. 4-1812".

75 ADC, Edictos imprełos, número 129.

76 ADC, Edictos impresos, número 132. 
libros, folletos y papeles impios y blasfemos unos, subversivos de toda autoridad y religion otros, corruptores de la sana moral y obscenos muchos, denigrativos de los ministros del santuario aquéllos y todos o casi todos llenos de hiel contra el trono y el altar" (Edicto del prelado Domingo de Silos Moreno, 15 de octubre de 1825) 77 .

"Las particulares circunstancias de su capital Cadiz por la franquicia de su puerto exigen en el dia una señal de atencion nuestra sobre ella a fin de que a la sombra de su libre comercio no se introduzcan los errores y costumbres consiguientes a ellos" (Domingo de Silos Moreno, 16 de diciembre de 1829) ${ }^{78}$.

$\mathrm{Y}$, lo que es más grave, la Iglesia gaditana parecía estar poco prepada intelectualmente para enfrentarse a estos nuevos problemas. El obispo Domingo de Silos Moreno no tenía recato alguno en denunciar la situación en 1827:

"No se oculta a este supremo natural el daño casi irreparable que de medio siglo a esta parte han sufrido las ciencias eclesiasticas y las que tienen estrecha relacion con ellas no puede ignorar tampoco que a proporcion que se ha introducido la novedad y el licencioso modo de pensar de discurrir y de obrar se haya debilitado el influjo de la Iglesia el aprecio de sus individuos y por consecuencia legitima el apego y aficion a alistarse en el numero de estos. Las dos ultimas convulsiones que ha sufrido la lglesia de España a rechazo de las que han conmovido a toda la Europa han llegado a introducir el hastio a todo lo que huele a teologia canones y literatura eclesiastica. Prueba de esta verdad es el corto numero de individuos que en las universidades se dedican a estas facultades...de tal desprecio y abandono han resuttado la escasez que se experimenta de letrados instruidos juiciosos y sabios cuales se requieren para ejercer la judicatura en los tribunales eclesiasticos. Y si se puede decir que existen aun hombres eruditos y que pueden desemperiar el delicado y espinoso encargo de provisores sin echar mano a los deanes doctorales y otros a quienes esta prohibido dicho oficio tambien es preciso confesar que las nuevas y peligrosas doctrinas favorecidas de los ultimos tiempos han fascinado a muchisimos y por lo mismo no es de extrañar que sea muy dificil escoger entre tantos preocupados y engolosinados con la modernidad"79.

El contenido de las bibliotecas eclesiásticas nos confirma esta falta de bagaje intelectual apropiado para enfrentarse a los nuevos tiempos. La librería del prelado Juan Acisclo de Vera y Delgado, que a su muerte en 1818 contaba con varios centenares de volúmenes, está excesivamente centrada en cuestiones de teología, derecho canónico, y, como distracción, algo de literatura e historia, y lo más radical que encontramos es una representación de autores regalistas y filojansenistas (la Teologia de Natal Alejandro, las Antiguedades cristianas de Selvagio, las Obras de Van Espen, la famosa traducción de la Biblia realizada por Felipe Scio), con una escasa incidencia de la Ilustración (la Historia Natural de Buffon, unas "Cartas inglesas" posiblemente las de Voltaire, unas obras de Pope, las "Cartas persianas" de Montesquieu en inglés), posiblemente contrarrestada por la apologética conservadora, como La

77 ADC, Edictos impresos, número 139.

78 ADC, Edictos impresos, número 142.

79 ADC, Secretarfa, Despacho Silos Moreno, Cabildo catedial.

De la Iglesia Andaluza

Hispania Sacra 48 (1996) 
Falsa filosofía de Ceballos. Nuestro obispo, eso sí, poseía bastantes libros no sólo en latín, sino en italiano, francés e inglés, pero la impresión global que nos da es la de una cierta incapacidad, al menos a tenor del contenido de su librería, para comprender ( $\mathrm{y}$ menos para aceptar) debidamente las nuevas ideas que estaban difundiéndose ${ }^{80}$.

Y los religiosos, que tantas posibilidades tenían de influir ideológicamente en la feligresía, no se encontraban en una situación mucho mejor. Los mínimos de Alcalá, por ejemplo, carecían de libros en $1835^{81}$. Sus hermanos de religión de Puerto Real contaban en 1821 con 70 libros bastante estropeados, y solamente un Diccionario inglés nos muestra una cierta apertura cultural ${ }^{82}$. Tampoco los de Conil se encontraban en mejor situación, contando en 1835 con 60 libros "maltratados e incompletos"83 , o los dominicos de Alcalá, que ese mismo año tenían dos estantes con varios libros en mal estado ${ }^{84}$. La voluminosa biblioteca de los mercedarios gaditanos en 1835 se basaba fundamentalmente en libros religiosos, y nuevamente to más avanzado desde el punto de vista ideológico lo configura el filojansenismo de Natal Alejandro ${ }^{85}$. Tampoco en tamaño era despreciable la librería de los mercedarios de la Almoraima en 1821, aunque manteniendo un obsoleto bagaje cultural ${ }^{86}$, to mismo que la, mucho más reducida, de los agustinos de Chiclana en $1835^{87}$ o los mercedarios de Vejer en $1821^{88}$. El consevadurismo cultural, salvadas honrosas excepciones, de los eclesiásticos gaditanos (aunque nos faltaría contar con bibliotecas del clero secular o el cabildo catedralicio) les impedirá una contraofensiva ideológica eficaz.

\section{LA INCIDENCIA DE LOS VAIVENES POLÍTICOS.}

Y la misma era necesaria. Aunque ya durante la Guerra contra la Convención comenzaron a detectarse en el seno del clero gaditano diversos síntomas muy reveladores del rechazo suscitado por las nuevas ideas ilustradas y revo-

\footnotetext{
8i) ADC, Varios, leg. 2304.

81 AHPC, Hacienda, caja 1235.

82 AHPC, Hacienda, caja 1239.

*3 AHPC, Hacienda, caja 1257.

24 AHPC, Hacienda, caja 1257.

85 AHPC, Hacienda, caja 1235.

*6 AHPC, Hacienda, caja 1236.

87 AHPC, Hacienda, leg. 1236.

$8 *$ AHPC, Hacienda, caja $\$ 239$.
} 
lucionarias ${ }^{89}$, ello llegará a su paroxismo durante la Guerra de la Independencia, en la cual el estamento eclesiástico gadicense se comprometió al límite de sus posibilidades en la defensa de la Religión y de la Patria.

En primer lugar, a nivel económico. El cabildo catedralicio celebrado el 1 de junio de 1808 resolvía entregar todas las alhajas destinadas al culto divino, y el 4 de julio ya se había entregado la suma de $\mathbf{1 2 0 . 0 0 0 ~ r e a l e s ~ a ~ l a ~ J u n t a ~ l o c a l ~}$ de gobierno ${ }^{50}$. Y las aportaciones continuaron: una Nota de los donativos hechos por los habitantes de Cadiz con motivo de la presente guerra con Francia nos revela que en 1808 el prebendado Manuel de Cos aportó la suma de 11260 reales del subsidio, el cabildo eclestástico los 120.000 reales ya indicados más 1403 libras y 15 onzas de plata labrada (lo que hacía un total de 449.260), la Esclavitud del Santísimo Sacramento 4000 reales, el obispo 13.000 reales y menaje por valor de otros 12.000 , la Junta de la Obra de la nueva catedral 45.000 , la Orden Tercera de San Francisco $6000 . . . Y$ la colaboración material con la causa de las armas españolas no se limitó ahí: el 7 de enero de 1809 el cabildo catedralicio acordaba tener a su cargo la guardia de la Puerta del Mar de la urbe gaditana, aunque poco después manifestara la inutilidad de este servicio ${ }^{91}$, y el 15 de abril de 1810 los prebendados se hacían cargo de la administración de los hospitales de Cádiz y La Carraca ${ }^{92}$.

A este auxilio material, se le unió la continua busca del favor divino por medio de periódicas rogativas encaminadas a la obtención del auxilio para la justa causa de las armas españolas, las cuales fueron constantes durante todo este período: tal como se reconocía el 28 de octubre de 1810, para conservar la moral de los fieles era necesario "mantener el culto divino en todo su esplendor sin que decaiga"93. Y, finalmente, el clero gaditano prestó el necesario bagaje ideológico a la lucha por medio de las consabidas referencias al Altar, el Trono, y los desmanes cometidos por los franceses. Las muestras de ello son continuas: el edicto del Provisor y Vicario General José Muñoz Raso del 16 de enero de 1809 en el que ordena a los clérigos "imprimir en los corazones de todo el pueblo los mas intimos sentimientos de la religion santa mediante los cuales se formaran generosos campeones que subyuguen los mas vastos imperios y se obstenten fuertes en la campaña hasta abatir por tierra todos los ejercitos enemigos ${ }^{1+94}$, el edicto posterior del 15 de septiembre de

\footnotetext{
89 Morgado GarCla, A., "El clero gaditano y la Guerra contra la Convención (1793-1795)", $V$ Enctuentros de la llustración al Ronanticismo, Cádiz, 1989.

90 ACC, Sección 1, serie 1, lib. 56 y 68v.

91 ACC, Sección 1, serie 1, lib. 47, fols. 15 y 104.

92 ACC, Sección I, serie 1, lib. 47, fol, 42v.

93 ACC, Sección 1, serie 1, lib. 47, fol. 16.

94 ADC, Edictos impresos, número 119 a. 
1809 en que muestra cómo "los altares santos robados profanados y prostituidos, sus ministros unos degollados otros perseguidos y todos desacreditados, la religion de nuestos padres menospreciada, hollada y calificada de fanatismo, sus institutos santos mofados, calumniados y aun abolidos, las virgenes del inmaculado esposo insultadas, violadas y arrojadas de su pacifica, inocente y santa clausura, mientras leyes pospuestas a una constitucion, parto de la arbitrariedad y de la perfidia, nuestro legitimo rey cautivo por engaños y traiciones, su real familia confinada con el mayor de los descaros, y la mas atroz de las violencias, la nacion toda ultrajada y calificada como una insensible gavilla de esclavos o insurgentes, y esto por un corso imprudente sin probidad ni religion, enemigo de todos los reyes, perseguidor de la iglesia santa, opresor de su pontifice" 195 ...

La buena entente entre la Iglesia gaditana y los poderes públicos se rompería poco después de la promulgación de la Constitución de 1812. Aunque en principio la actitud hacia las Cortes había sido bastante amistosa (el 5 de octubre de 1810 el cabildo catedralicio organizaba una rogativa por su apertura, el 12 prestaba juramento de obediencia a las mismas ${ }^{96}$, el 30 de agosto de 1811 se organizaban nuevas rogativas "implorando las luces que necesita el congreso para hacer el arreglo y mejora de la constitucion politica de la monarquia de modo que pueda lograr la nacion toda la felicidad y prosperidad a que aspira principalmente la de conservar para siempre su santa religion y el ver restituido al trono a su rey"97, el 6 de junio de 1812 se juraba la constitución ${ }^{98}$, todo cambiaría ante la exigencia de leer en las iglesias de la ciudad el decreto por el cual las Cortes resolvían la abolición del tribunal de la Inquisición ${ }^{99}$.

En principio, el cabildo catedralicio evitó un enfrentamiento directo, de tal modo que el 4 de marzo de 1813 se acordaba "obedecer y no cumplir" el mandato constitucional ${ }^{100}$, aunque alguno de sus miembros, como el lectoral Antonio Manuel Trianes y el magistral Antonio Cabrera, se negaran a firmar la representación dirigida por el cuerpo capitular a las Cortes sobre esta cuestión ${ }^{101}$. Todo ello acabaría provocando la detención de los prebendados más comprometidos con esta resistencia, el arcediano de Medina Pedro Juan Servera, los prebendados Matías de Elejaburu y Manuel de Cos y el vicario capi-

95 ADC, Reales Ordenes, leg. 20, "Oficio dirigido al canonigo in sacris por el intendente D. Pedro Simon de Mendirueta exhortando al clero a servir de capellanes Cadiz 24-8-1809".

${ }^{96}$ ACC, Sección $\mathrm{t}$, serie 1, lib. 47, fols. 112 y 114.

97 ACC, Sección I, serie 1, lib. 47, fol. 66.

${ }_{98}$ ACC, Sección I, serie 1, lib, 48, fol. 33 .

99 La polémica provocada por esta medida en SoLIS, R., El Cádiz. de las Cortes, Madrid, 1958, pp. 328 ss.

100 ACC, Sección 1, serie I, lib. 48, fol. 19.

101 ACC, Sección 1, serie 1, lib. 48, fol. 20v. 
tular Mariano Martín Esperanza' ${ }^{102}$, al que el cabildo de canónigos in sacris del 10 de julio de 1813 pretendiera sustituir por el canónigo Francisco de la Plaza!03 (lo que de paso provocó un acre pleito contra esta medida que llegaría al tribunal metropolitano de Sevilla e incluso al Tribunal de la Rota, que resolvería en 1816 declarar como nula la elección de Plaza) ${ }^{104}$. Los prebendados enjuiciados, una vez restablecido Fernando VII en el trono, viajaron a Madrid en 1814 para entrevistarse con el monarca, visita reflejada en el Discurso de los señores comisionados del llmo. cabildo de la SIC de esta ciudad de Cadiz. pronunciado en presencia de Don Fernando VII publicado en Cádiz en 1814, donde exponían cómo "nosotros imperturbables en nuestros principios de religion y firmes en el proposito de llenar nuestros deberes supimos rechazar con vigor los primeros sus ataques y sostener con dignidad los sagrados derechos del santuario cuando intentaron profanarlo con la lectura de un decreto inicuo y de un manifiesto lleno de falsedades", publicando bajo sus auspicios, asimismo, la Memoria interesante para la historia de las persecuciones de la Iglesia catolica y sus ministros en España en los ultimos tiempos de cautividad del señor Don Fernando VII el Deseado (Madrid, 1815), donde se encuentra una detallada narración de todos estos enfrentamientos y una defensa del tribunal de la Inquisición, que "impedia el libre ejercicio a los propagandistas de la impiedad".

No obstante, la actitud hostil no fue ni mucho menos unánime en eI seno del clero gaditano. El prepósito de la congregación de San Felipe Neri, Joaquín Alvarez, llegaría a escribir una felicitación a las Cortes en agosto de 1813, ya que en ellas "se discutio y sanciono la constitucion de la monarquia, esta obra admirable de la sabiduria y beneficencia" 105 . El cura de Algeciras, Vicente Terrero, en su Sermon sobre la constitucion politica de la monarquia española (Algeciras, 1814) aludirá a ese "volumen reducido pero a la verdad copioso de leyes saludables que exacta y religiosamente custodiadas afianzaran la gloria de la nacion". Y ya hace muchos años que se conoce la actitud favorable a las ideas liberales del magistral Antonio Cabrera ${ }^{106}$ o del lectoral Antonio Manuel Trianes.

Constituirán, empero, una minoría. Durante el Sexenio la inmensa mayoría del clero gaditano tomará partido por la renovada alianza entre el Altar y el Trono, y se tomarán las pertinentes medidas contra aquellos eclesiásticos más díscolos desde el punto de vista ideológico: uno de ellos, el cura Manuel Ga-

\footnotetext{
102 ACC, Sección 1, serie 1, lib. 48, fol. $32 \mathrm{v}$.

103 ACC, Sección 1, serie 1, lib. 48, fols. 57v-58.

104 ACC, Sección 1, serie 1, lib. 50, fols. 2Il-218.

its ADC, Secretarí, leg. 75.

Iow SOLIS, R., op. cit., p. 306.
} 
liano, fue depuesto en 1814 de su destino en la catedral, aunque sería restablecido tres años más tarde, llegando en el Trienio a ser elegido capellán de la milicia local ${ }^{107}$. Al mismo tiempo, la jerarquía condenará sin ambages cualquier conato subversivo: el 13 de septiembre de 1819, ante el requerimiento de los comisionados de la corona para la investigación de los sucesos acaecidos en el Palmar del Puerto de Santa María, el cabildo catedralicio responderá no tener "datos de ninguna clase para ilustrar en materia tan ardua, pues el alto clero siempre es sospechoso a los ojos de los facciosos para empresa de este orden y harto conocido es su interes por la conservacion de la monarquia que los individuos de este cabildo fuesen sorprendidos en la incidencia del dia ocho" 108 ; el 4 de enero de 1820 , ya iniciada la sublevación de Riego, los prebendados se ofrecieron al Gobemador de la ciudad para todo "cuanto conduzca al bien de la tranquilidad publica y conservacion de la fidelidad al rey"109, cinco días más tarde el prelado Francisco Javier Cienfuegos publicará su famoso edicto "Contra los lobos rapaces..." en el que expone cómo "la religión no ha autorizado ni autorizará jamas las rebeliones aun cuando pudiera haber motivos a primera vista fundados de queja por el contrario ella nos enseña que debemos obedecer a los principes aunque sean discolos...la religion y nuestro propio interes os estimulan amados hijos mios a perserverar constantemente adheridos al trono de nuestro legitimo soberano tan digno de nuestro amor y respeto como injustamente perseguido por los facciosos que no merecen el nombre de cristianos ni de españoles"110.

Dentro de este ambiente de reacción ideológica, habría que aludir al restablecimiento de los jesuitas en la urbe gaditana, para lo que intercedían los munícipes gaditanos ante el monarca el 24 de octubre de 1814, exponiendo cómo "nuestra España que tomó parte activa en la extincion de la Compañia de Jesus empezo a sentir por pasados los mismos males que mucho antes habian arruinado al clero de Francia y a su monarquia, los tronos estaban ya amenazados o por la falaz politica de la secta filosofica y las relaciones de una y otra potencia se hacian servir para que descendieran los soberanos al anismo del desprecio republicano...la educacion señor esta muy pervertida los principios sanos para nivelar las costumbres puestos en ridiculo la subordinacion a las leyes justas y a las potestades ordenadas y legitimas repugna al desenfreno que han tomado las pasiones lo mas sagrado de la religion que nos distingue entre todas las naciones del mundo se mira como un oprobio de la humanidad se hace alarde de saber cuanto conviene con solo el estudio de la secta filoso-

\footnotetext{
107 ADC, Reales Ordenes, leg. 25.

108 ACC, Sección 1, serie 1, lib. 5I, fols. 153v-154.

(t) ACC, Sección !, serie !, lib. 51, fol. 2.

110 ADC, Edictos impresos, número 132.
} 
fica...estos desordenes han tenido todo su progreso desde el triempo del extrañamiento de los jesuitas"II'. No fue, empero, un proceso fácil: buena parte de las propiedades y el mismo edificio del colegio de la Compañía habían pasado al seminario de San Bartolomé ${ }^{12}$, en situación muy precaria dado sus atrasos económicos y los deterioros de las tropas alojadas en el mismo durante la Guerra de la Independencia ${ }^{113}$, por lo que en seguida alegó los daños económicos que se seguirían de la retrocesión a los jesuitas de sus propiedades, siguiéndose unas difíciles negociaciones que culminarían cuando en 1817 se acordara ceder a los jesuitas la iglesia de Santiago con todos sus censos y posesiones, la veintena de las rentas de fábrica del obispado y el edificio ocupado por el seminario, al que se compensaría con las rentas del beneficio de Nuestra Señora de la Ina cuando éste quedara vacante ${ }^{114}$.

Una vez implantado nuevamente el régimen liberal, se impuso una actitud más posibilista. El propio cabildo catedralicio juró la constitución el 21 de marzo de $1820^{115}$, y Francisco Javier Cienfuegos promulgaría un nuevo edicto el 19 de mayo de 1821 en el que exhortaría a los fieles "a la puntual observancia de la constitucion politica de la monarquia española que todos hemos jurado, al respeto y obediencia a las autoridades legitimas, que nos gobiernan y a sus decisiones y a conservar la paz y tranquilidad publica sin lo cual no pueden ser felices las naciones $116 "$. Algunos eclesiásticos, nuevamente, se caracterizarían por una actitud sinceramente liberal: el cura Antonio Romero en el Sermon predicado en la solemne fiesta del juramento de la constitución de la monarquía española (Cádiz, 1820) afirmará cómo "el gran Dios de las misericordias que vela sobre los hombres y mas admirablemente sobre los españoles, suscito tantos hombres sabios, hombres prudentes, hombres amantes de su religion, de su rey, de la patria, que unidos formaron este precioso libro de la constitucion politica de la monarquia española", el lectoral Antonio Manuel Trianes en su Discurso exhortatorio (Cádiz, 1821), expondrá cómo "somos libres y dichosos por el benefico influjo de un codigo de leyes sabias que sera eterno monumento de los progresos del conocimiento huimano y de la civilizacion de las naciones", Algunos llegarán incluso a una fuerte radica-

Iit AMC, AC, lib. 174, fols. 427-430.

112 MORGado GarCla, A., "La reforma del seminario de San Bartolomé (Cádiz) en el siglo XVIII", Anales de la Universidad de Cádiz, V-VI, 1988-1989.

113 Morgado Garcia, A., "Los alumnos del seminario de San Bartolomé", Gades, 18, 1988.

114 Numerosas referencias sobre estas negociaciones en AMC, AC, lib. 180.

115 ACC, Sección I, serie I, jib. 5I, fol. 33v.

$116 \mathrm{ADC}$, Edictos impresos, número 133.

De la Iglesia Andaluza

Hispania Sacra 48 (1996) 
lización ideológica, como el célebre José Joaquín de Clararrosa ${ }^{117}$, cuyas obras tanta controversia suscitaran ${ }^{18}$.

De todas formas, el entendimiento duró poco, y casi inmediatamente comienzan a observarse en el seno de la Iglesia gaditana posturas hostiles hacia el nuevo régimen. El cabildo municipal del 1 de diciembre de 1820 exponía cómo en la noche anterior hubo una reunión del pueblo solicitando la separación de varias personas de la ciudad, entre ellas el prelado Francisco Javier Cienfuegos, acordándose tomar medidas vigorosas contra todos los eclesiásticos que indujeran al pueblo a creer "que se pierde la religion bajo el sistema constitucional o directa o indirectamente desacreditan las nuevas instituciones", y que se le hiciera entender al obispo lo inconveniente de su regreso a la ciudad de su visita pastoral ${ }^{119}$. El 28 de abril de 1821 se daba la noticia de un sermón publicado en la catedral el día 25 por un descalzo apellidado Carambano en que se hablaba mal de la constitución ${ }^{120}$, el 30 de abril de 1821 se solicitaba por parte del pueblo el arresto del obispo, el chantre Juan Nepomuceno, y los canónigos Matías de Elejaburu, Manuel de Cos y Bonifacio Casteli ${ }^{121}$...la entente entre la Iglesia gaditana y el Nuevo Régimen no podía durar. Las secularizaciones de los religiosos, las nuevas desamortizaciones y los ataques a la religión explican esta postura visceralmente combativa ${ }^{122}$, a lo que se se unirá la obligada ausencia del obispo Francisco Javier Cienfuegos durante casi todo el transcurso del Trienio ${ }^{123}$.

Triunfante de nuevo el absolutismo recalcitrante, la reacción ideológica no tardaría en llegar, con el corolario consiguiente de persecuciones políticas contra todos aquellos eclesiásticos comprometidos con el régimen anterior. El obispo Francisco Javier Cienfuegos ordenaría un expediente general del clero, y en Medina Sidonia hubo una serie de inculpados por ser miembros de sociedades patrióticas, de juntas secretas, de alterar el orden público, de propaganda anticatólica, de perseguir a realistas y de no asistir a los actos conmemora-

117 Vid. Ravina Martin, M., "El entierro de un masón: José Joaquín de Clarartosa (1822)", Revisla de Historia Contenporánea, 1, 1982.

118 Una muestra de ello, en el Catecismo critico dogmatico sobre varios puntos de los escritos del famoso Jose Joaquin de Clararrosa por un liberal catolico (San Fernando, 1821), o Contra el pretendido triunfo de la Concordata, defensa de las verdades católicas y refutación de los errores de la teoria y ientativa de Clararrosa por wn sacerdote C.A.R. (Cádiz, 1820).

${ }^{19}$ AMC, AC, lib. 186, fols. 306-307.

$120 \mathrm{AMC}, \mathrm{AC}$, lib. 188 , fol 183 v.

[2] AMC, AC, lib. 188 , fols. 187 v y 188 .

122 Una visión de conjunto sobre Ja Iglesia gaditana durante el Trienio en GARCIA LEON, J.M., Cádiz en el Trienio Liberal, vol. 1, Cádiz, 1988, Tesis doctoral inéditn, pp. 31 1-317.

12.3 Una detallada relación de las cuitas padecidas por el obispo en la Visita ad limina de 1824 (ASV, Visitas ad limina, Cádjz, copia existente en el Archivo Diocesano de Cádiz). 
tivos de la Restauración de Fernando VII ${ }^{24}$. Del cura de San Roque ManueI Villalba se confeccionó un grueso expediente en el que se indicaba cómo "protegio la asonada que hizo a la fuerza que se jurase la constitucion...instalo la secta reprobada de comuneros rigio las asonadas nocturnas persiguio a los que se manifestaron fieles y adictos al legitimo gobierno fue permanentemente en los cafes con los de su faccion paso el tiempo en desordenes escandalosos que produjeron funestos resultados y estuvo refugiado en la plaza de Gibraltar cuando supo se acercaban las tropas aliadas y realistas a aquel campo en el año de 1823", siendo depuesto de su curato por el obispo ${ }^{125}$. El lectoral Antonio Manuel Trianes fue denunciado en 1826 por el gobernador Aymerich por ir "siempre acompañado de personas de muy mala nota por sus opiniones y adhesion al abolido sistema constitucional"126. El presbítero de Jimena Francisco González fue acusado en 1824 de "concurrir a los atentados criminales que los revolucionarios prepararon proclamando la constitucion con vivas y muera el rey, vivan los ingleses y mueran los franceses, viva la igualdad y viva la libertad con otras muchas expresiones subversivas", aunque en un auto del 26 de noviembre de 1825 el vicario general de la diócesis reconociera la inexistencia de pruebas concluyentes contra su persona ${ }^{27}$.

Al mismo tiempo, el púlpito seguirá siendo utilizado para la contraofensiva ideológica. El franciscano observante Fray José María Laso de la Vega en su Sermón de desagravios (San Fernando, 1823), tras afirmar que "la religión católica es la única que en estas enfermedades horribles de las naciones que llamamos revolucion puede hacerse oir de todos los partidos...la religion solamente hace firmes los tronos y fuertes y venturosas las naciones, si la religion falta caen los tronos y las naciones mueren", interpreta los sucesos acaecidos en Francia y en la Europa entera como consecuencia de la pérdida de la misma. El mismo, pocos años después, en el Sermón que en la beatificación de la Sra. Doña Juana de Aza (Cádiz, 1829), volverá a aludir a la irreligión de Federico el Grande, Voltaire y Napoleón, y a los sufrimientos, gloriosamente superados, de la Iglesia como consecuencia de ello.

Fray Domingo de Silos Moreno, obispo desde 1825, será el último prelado que ocupará la sede gaditana durante estos turbulentos años. No tan fogoso como su predecesor Francisco Javier Cienfuegos, hubo, empero, de tomar partido en alguna ocasión por el gobierno fernandino, como refleja su pastoral

\footnotetext{
124 Cuenca Toribio, J.M., "El proceso de curas liberales en Medina Sidonia (Cádiz) de 1823. Notas para el esutdio de la segunda testauración religiosa en la España contemporánea", Ertudios sobre la Iglesia andaluza moderna y contemporánea, Córdoba, 1980.

12.5 AHN, Consejos, leg. 15649, exp. 3.

126 ADC, Secretaría, Despacho Silos Moreno, Gobernador y comandante genernl.

127 ADC, Secretaría, leg. 86. 
El obispo de Cádiz a sus diocesanos con motivo del asesinato cometido en la persona del señor Gobernador de esta plaza (Cádiz, 1831), promulgada con motivo del asesinato del gobernador Aymerich, en la que exhorta a los fieles a no dejarse llevar "de las falaces promesas de libertad, independencia e igualdad, con que intentan seduciros los que quieren dominar a todos y no sujetarse a nadie. Esas mismas promesas hizo el Príncipe de las tinieblas a nuestros primeros padres...eso de ser iguales, independientes y libres en el sentido que lo explican los libritos del dia, y que tanto cacarean los que se itutlan amigos de los hombres, es una quimera". Si tenemos en cuenta que nuestro buen prelado, ante la epidemia de cólera de 1832, seguía buscando una explicación escatológica ("Este Señor irritado al ver que toda carne ha corrompido su camino... le castigue por lo menos con el equivalente de males, trabajos y calamidades que sin cesar se han experimentado en estos aciagos tiempos") ${ }^{128}$, comprenderemos sin ningún género de dudas la profunda incapacidad de la Iglesia gaditana para enfrentarse de forma serena y ponderada ante las radicales transformaciones que en breve iban a tener lugar.

${ }^{128}$ El obispo de Cádiz a todos sus diocesantos con motivo de la enfermedad llamada colera morbo, Cádiz, 1832. 